\title{
Roofing and thawing the sub-Arctic city. Towards the conceptualisation of well-being through urban surfaces
}

\author{
Essi Oikarinen \\ University of Oulu, Oulu School of Architecture, Finland \\ essi.oikarinen@student.oulu.fi
}

\begin{abstract}
An increasing amount of sub-Arctic population is living in cities and settlements. Despite the urbanisation, seasonality still affects the rhythm of life and willingness to spend time outside of home, which, in turn, affects health and wellbeing of the population. In addition to built artefacts, the materiality of sub-Arctic urban environment consists largely of changing weather conditions and seasonality, including phenomena such as thawing, freezing, snow, ice and slush, which have diverse effects on humans using the urban spaces, yet are not often part of conceptualisations of urban space that are formed in southern climates. In this paper, the relationship between sub-Arctic urban form, climate and users of the urban realm is critically re-evaluated using the concept of surface. Based on a review of the literature, the proposed approach gives agency not only to the weather, but also to different types of people inhabiting the urban space. This paper argues that the proposed approach takes better into account the varied nature of sub-Arctic urban spaces and their affordances as an entity: from privatised, roofed and weather-neutralised shopping centres and arcades to sledding hills, skating rinks and other winter-related spaces. This kind of conceptualisation could be beneficial when developing soft mobility plans for northern regions. Encouraging physical activity has direct effects on the physiological health of the population, but in addition to that, the approach attempts to acknowledge personal control of different user groups as a central aspect of wellbeing, which makes the viewpoint more holistic.
\end{abstract}

Keywords: sub-Arctic climate, well-being, affordance, surface, urban design, everyday life

To cite this article:

Oikarinen, E. (2020). Roofing and thawing the sub-Arctic city. Towards the conceptualisation of wellbeing through urban surfaces. The Journal of Public Space, 5(2), 45-62, DOI I0.3289I/jps.v5i2.I28I

This article has been double blind peer reviewed and accepted for publication in The Journal of Public Space. (c) This work is licensed under a Creative Commons Attribution - Non Commercial 4.0 International License https://creativecommons.org/licenses/by-nc/4.0/ 


\section{Introduction}

In recent years, the role of nature (meaning the most often greenery) in urban environments has been researched from socio-spatial, cultural and technical viewpoints (Watson, 2017; Loughran, 2016), which have enlarged both the nature's and the inhabitants' role as active agents in the urban environment. Yet, there is still a lack of such approach for the 'white space' - snow and ice specifically, which are prominent features in northern climate zones. This is most certainly linked to research of green space, but in similar vein that 'blue space', meaning the bodies of water, has been argued to become rather an analogy than a subcategory to green space (Volker \& Kistemann, 20II), white space also requires an approach of its own.

The northern urbanity is much younger than, for example, Mediterranean urbanity, which has raised questions on the suitable northern urban structure - more specifically sub-Arctic and Arctic cities. Geometric and compositional properties of traditional European architecture (such as open spaces, treed alleys and boulevards) have been deemed inappropriate for cold, snow-ridden towns and cities (Pressman 1996). Thus, the northern urban realm has been a site for many kinds of competing ideologies in recent decades. In the spirit of Modernist mega structures in the latter part of the $20^{\text {th }}$ century, northern urban cores were extensively protected with roofed spaces, malls and passageways - leading into large commercial environments, such as skyway system in Montreal. To oppose the development, the so-called Winter City Movement coined up in the 1980s opposed the energy-intensive, protected indoor spaces in the spirit of New Urbanism: the ideal sub-Arctic city became small-scale, dense and walkable. Ideally, the climatic comfort was achieved through microclimatic considerations instead of intensive energy use (i.e. Kuismanen, 2008). Norman Pressman, an advocate for the concept of so called 'winter cities' since the 1980s, maintains that we should not consider winter as merely something to protect people from, but also expose people to the positive aspects of the climate - local climate is a productive aspect of design (Pressman, 1996). For example, sub-Arctic climate also provides recreational opportunities, which have been acknowledged by northern cities in recent years as endeavours to activate the urban life and economy during the winter season (i.e. City of Edmonton, 2012; City of Oulu, 20I4). Winter is not necessarily a new function requiring more space or repurposes, but a condition which affects the use of space and activity patterns in general. In sub-Arctic climate, the weather is a major determinant of people's decision-making about outdoor activities (Ebrahimabadi et al., 20I5). This, of course, has also implications for the health and wellbeing of the inhabitants of subArctic cities. Physical inactivity is considered to be the 4th leading cause of death worldwide contributing to mortality (Kohl et al., 20I2) - thus, from the point of view of physiological health it is important to design environments that encourage exercise for different groups of people. Exercising outdoors in natural environments is also beneficial for various aspects of mental health (Thompson Coon et al., 20I I). However, physical activity is conditioned by psychological aspects, such as perceptions and emotions (Eliasson et al., 2007), and personal control has been found to be an important mediating variable to reduce the negative psychological effects of environmental stress ( $\mathrm{Li}$, 1994). These viewpoints are often not discussed together. The World Health Organisation (WHO) introduced a broad definition of health already in the late 1940s. According to WHO, health is not only the absence of disease but a 
state of complete wellbeing in a physical, mental, and social sense. Urban design cannot be fully charged with delivering human health and wellbeing objectives, but it can support humans in their choices: i.e. drugs, overeating and under-exercise are some of the factors of modern life that determine the pathological pattern of disease despite of the high standards of living. The possibility to choose and change the environment is central to wellbeing: health promotion could also be defined broadly as a "process of enabling individuals, groups or societies to increase control over, and to improve their physical, mental, social and spiritual health" (Eriksson \& Lindström 2007, p. 943). Defined in this way, the climate control is not just about functionality of the urban realm but concerns broader socio-cultural needs. In addition to the needs of the individuals, according to the New Urban Agenda (United Nations, 2016), the future cities should be people-centred and participatory, for example, engender a sense of belonging and ownership, but at the same time protect the planet.

Referring to the definition of wellbeing as active participation and ownership, as defined above, I argue that these aspects have not been adequately discussed in the research literature on urban space and climate. This discussion is important since it seeks to enlarge the concept of public realm to include humans as active actors in their own wellbeing. Through a review of the literature, this paper aims to develop a conceptualization of climate and its consequences on urban realm on a micro level, as a site for everyday life of the inhabitants - as practices and performances instead of systems or structures (de Certeau, 1980). The paper argues that this lived reality and socially produced entity of urbanity (Lefebvre, 1992), which is marked by a rhythmic, temporal structure and repetitive actions (Lefebvre \& Nicholson-Smith, 1991), holds potential to look at sub-Arctic urban environment from a new epistemological perspective. The paper begins outlining the recent research on the relationship between sub-Arctic climate, urban spaces and wellbeing impacts. Then later it moves on discussing the concept of surfaces and its potential in discussing the impacts of climate and weather on experiencing the urban space. The paper also illustrates the theoretical discussion with photographs from sub-Arctic city centres of Oulu, Finland, and Luleå, Sweden (2016-2018) (figures 2-10). Luleå, a city of 46,600 inhabitants, is located about $110 \mathrm{~km}$ south of Arctic Circle. Oulu is bigger with its 199,500 inhabitants and the distance to Arctic Circle is around $160 \mathrm{~km}$. Finally, it is proposed that looking closely at bodily, everyday life experiences in urban environment might help with defining its desired qualities and eventually might help with forming holistic design strategies for the sub-Arctic cities.

\section{Sub-Arctic climate, urban form and their implications on wellbeing}

This section collects recent empirical research and viewpoints discussing the relationships between sub-Arctic climate, urban form and inhabitants. The focus is on research done in the sub-Arctic climate zone, but some more general theories explaining the relationship to the users and observers of urban space are included as well, when applicable.

2.I. Climate and the perceived spatial composition of the public realm During the winter season, sub-Arctic public space is physically changed by the covers of the season - like snow, slush and ice. This reduces ease of understanding of the public 
realm and townscape, spatial structure and pattern of streets (Chapman \& Larsson, 2019). Thus, seasonality and climate become a part of the spatial arrangement

(Chapman 2018). In other words, the immaterial features of landscape become a part of the material design of the urban form (Labadini, 2017). Chapman et al. (2019) argue that urban realm in the winter is both more ambiguous for the observer because of piles of snow and hidden road surface markings, for example, yet also provides new opportunities, such as shortcuts through the frozen bodies of water.

It is not only the microclimate itself that people perceive but also the spatial settings in which it happens (Lenzholzer, 2010). Spatial qualities and space type, such as different materials and heights of the buildings, change the experience (Lenzholzer, 2010; Eliasson et al., 2007). Lenzholzer's research (2010) in a moderate climate in Central Europe suggests that most microclimate perceptions in relation to space are accurate when compared to physical measurements. However, sometimes the physical circumstances and perception are not congruent: this concerns for instance people's overestimation of wind influences and their association of 'cold' colour tones with a cold thermal experience, which is not necessarily based on physical reality (Lenzholzer, 20I0). In addition to colour, naturalness also affects the experience and people reportedly enjoy the cold weather more in natural settings compared to urban (Westerberg, 2000).

\subsection{Climate and the willingness to perform certain activities}

Like in all climates, also in the sub-Arctic climatic zone the climate and weather have direct health effects. There are certain specific conditions related to northern environment, such as seasonality affective disorder (SAD). Following the broader definition of health and wellbeing, bad weather affects mobility and accessibility of the urban environment in general, resulting in decreased amounts of being outside. On the level of an individual, there is an established connection between regular physical activity and individual health and wellbeing (Kohl et al., 20I2). In general, the modern lifestyle, entangled in monitors, discourages exercise and activity both in work and leisure hours, it is stated that people spend $90 \%$ of their lives within buildings (Evans \& McCoy, 1998). In cold climates the rate is even higher: in Finland people spend 4\% of their time outdoors during winter, and most of it during their leisure time (Mäkinen, 2007).

Weather is a major determinant on people's decisions about outdoor activities and soft mobility in cold climates (Embrahimabadi, Nilsson \& Johansson, 20 I5). Winter reduces connectivity for soft mobility by reducing the number of routes and pathways and limits the useable space in the public realm. Main barriers to soft mobility are icy surfaces and rain, as well as coldness, darkness and wind. Snow and snow-covered surfaces have the least impact (Chapman, 2018). The relationship between functional use and microclimatic conditions has been confirmed by several studies (see Eliasson et al., 2007) which show that comfortable weather conditions, i.e. high temperature, clear sky and access to sunlight increase the number of people present in an urban space in a subArctic climate. Ebrahimabadi (2015) issues provision of sheltering from the wind, maximising solar access, and managing snow as the most crucial for improving environmental comfort in sub-Arctic climate. Seen in this way, climate becomes a background which hinders or favours certain affordances and activities but is not the main feature of the environment as such. In other words, climate controls activity. Carmona et al. (2003) have named this 'climate-sensitive urban design': microclimate is seen to affect how accessible the (non-climate-related) design affordances are for the 
user. For example, a park bench might be a desirable place to sit when it receives the rays of sun during a warm summer day - but it might be completely inaccessible when covered in snow and not maintained during the winter.

\subsection{Climate and temporal activities}

Northern environments do have certain productive qualities, which enable experiencing the environment differently. Activities such as skiing, skating and sledding expand functionality of the climate from being a mere background for activity. Despite the soft mobility challenges that winter season poses, ice roads crossing the frozen bodies of water, for example, can be also perceived as positive affordance provided by the winter season (Chapman et al., 2017). The sub-Arctic climate also provides recreational opportunities, which have been acknowledged by especially northern cities in recent years as endeavours to activate the urban life and economy during the winter season (i.e. City of Edmonton, 20I2; City of Oulu, 20I4).

Contrasting the previously mentioned climate as a hindrance to activity, people enjoy experiencing different weather conditions - for instance, wind in the hair or dancing in the rain (Eliasson, 2000). The changing seasons are perceived as positive by some subArctic inhabitants - and embracing it provides a more sustainable, diverse and pleasant environment for inhabitants (Jauhiainen \& Mönkkönen, 2005). On the other hand, perceptions of a 'good weather' differ, depending on people's origin and cultural background (Thorsson et al., 2007). An approach that actively includes the experiences of climate within the design schemes has been named as climate-revelatory (Lenzholzer, 2012).

\subsection{Climate control and the values guiding urban design}

Jan Gehl (197I) presents a simple theory on how the microclimate influences social life in urban areas through dividing activities into necessary and optional. A social environment, according to Gehl, must have physical qualities that invite people to slow down, such as a favourable microclimate. If these qualities are absent and the microclimate is not pleasant, people just do what they feel necessary. Necessary activities are often a priority in urban design, yet optional activities are more vulnerable and therefore need special attention (Westerberg, 2000). However, it is culturally defined which activities are valued as necessary and which fall into optional. In order to prevent diseases related to high standards of living, a substantial amount of recent research has focussed on how to support year-round connectivity for soft mobility (i.e. Chapman 2018; Chapman et al. 2019). The question is also socioeconomical: Whom does the maintenance and control of wintry urban realm serve? In recent years, some municipalities in Nordic countries, especially in Sweden, have adopted gender-neutral ploughing strategies (99\% Invisible 2019$)$ - meaning that soft mobility routes often preferred by women are cleared before roads after a snowstorm. However, this kind of feminist perspective has not yet been specifically discussed in the context of sub-Arctic climate in academic research.

\section{What kind of model for sub-Arctic urban realm?}

Research states that climate considerations currently have low impact on urban planning practices in the sub-Arctic region: seasonality (Jauhiainen \& Mönkkönen, 2005) or 
comfortable microclimate (Ebrahimabadi et al., 2015) are not given enough consideration by planners. This is partly understandable, since the research outcomes discussed in the previous section also oppose each other. On the one hand, climate is an experiential feature that adds new functions and experiences to urban realm. On the other hand, its effects should be reduced.

It is also notable that malls, passageways and other roofed typologies that gained popularity in the $20^{\text {th }}$ century are currently not examined as part of the wellbeing impacts within urban design - the optimal climatic conditions are found from somewhere less protected, often emphasizing the benefits of nature. In contrast, public health projects have noted that indoor spaces are central parts of socio-natural systems (Biehler and Simon, 2010). This kind of polarisation between outdoors and indoors follows a broader discussion on urban space and its decline (i.e. Carmona, 2010). The critique of the decline of public space seems to be dichotomised: some critics focus on over management - an approach that manifests itself in what can be seen as commodification and homogenization of space. Other critics paint an opposite picture of under management of external public spaces, of a rubbish-strewn, poorly designed and insecure public realm. Also, discussion about winter maintenance seems to fluctuate between this dichotomy. The white space of the winter is difficult to comprehend, which leads to suggesting for example light projections to define space during the winter season (i.e. Chapman \& Larsson, 2019) or controlled indoor environments. At which point does maintenance turn into over management? Are all the indoor public spaces automatically over-managed and therefore not suitable to act as public spaces? These questions persist as long as we aim for controlling the space and climate for its users as passive targets of design solutions.

On the other hand, the ideal of constant climatic conditions - most easily achieved through roofed, indoor spaces - implicate that the city is considered as a building, and urban squares as 'rooms' in that building. This becomes problematic when cities are still obviously part of the surrounding nature, and ubiquitous natural processes still affect the urban areas (Lenzholzer, 2010). Therefore, urban design should develop a novel design paradigm. One that would be more inclusive of the climate processes and people's perceptions (Lenzholzer, 20I2) as well as bridge the inside and the outside of buildings as overlapping climatic zones, while acknowledging the materiality of the climatic phenomena instead of succumbing to the primacy of the visual (Roesler, 2016). To overcome the previously mentioned oppositions, I propose combining the effects between urban realm, climate and inhabitants (see Figure I). An examination of mundane everyday life through surfaces on which it happens, combines climaterevelatory elements and protected indoor public spaces into one socio-natural entity. More specifically, an integrated network of nature- and culture-based wellbeing affordances related to urban surfaces.

\section{Towards a conceptual framework: Surfaces of sub-Arctic urban space}

Especially during the last few decades, material turn in human and social sciences has revived interest in material relations and the role of materials in constituting the human world. Through material perspective, spaces are not seen as voids that accommodate activity, but as sites of constant exchanges between different matters. One of the conceptualisations is by James Gibson (1979) as he categorizes space into medium, 
substances and surfaces. Medium, most often air and gas, differentiates itself from solid substances, by affording the movement of solid bodies through it. It is also transparent and transmits light. (Labadini, 2017). Surfaces can be comprehended as an interface through which the environment is experienced through its qualities such as colour, texture, hardness, roughness, temperature, and so on. This comprehension might happen in substances or medium but are perceivable by human bodies on surfaces (Labadini, 2017). Surfaces can be only experienced through haptic vision: close-up, affective and kinaesthetic (Ingold, 20I7).

Tim Ingold (2017) gives a more active role to surfaces. He criticizes Gibson's conception for seeing the role of the surface as an interface between the relatively solid substances of the earth and the relatively volatile medium of the air. According to Ingold, surface should be seen as a variation intrinsic to the surface itself: the ground surface persists not in spite of reactions between substances and medium, but because of them. In the sub-Arctic urban realm, we perceive snow, rain and other climatic phenomena partly because they act with (urban) surfaces. This kind of viewpoint is close to a notion of milieu - both surfaces and milieu try to describe "a discontinuous and opaque field animated by the continuous emergence of sensual clues, in which humans are immersed" (Labadini, 2017, p. 46). Conceived in this way, the urban form becomes not primarily geometric but environmental. This kind of post-Cartesian notion of space is fruitful in understanding the climate and its effects in spaces, and the immaterial emerges as an integral and constitutive part of the space.

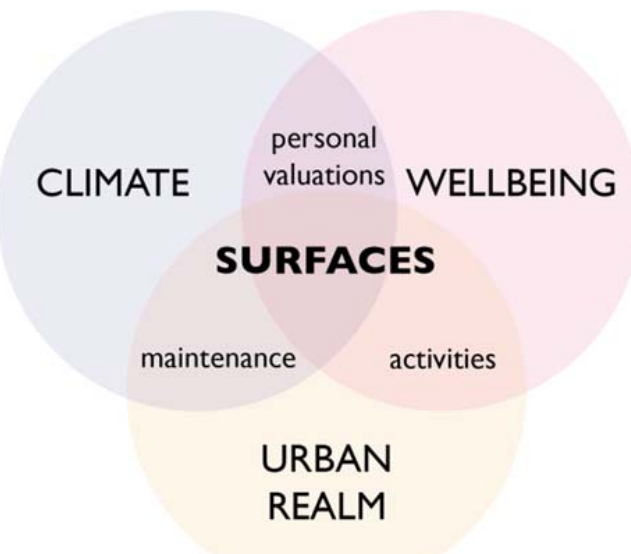

Figure I. Surface as a concept can be positioned in the intersection of climate, urban realm and the wellbeing of inhabitants. (Source: Essi Oikarinen)

In addition to connecting atmosphere and physical characteristics, in this case namely climate and urban form, surfaces can be also seen as sites for meaning. Tim Ingold (2017) argues, that the meaning of objects does not lie in their depths, but we need to look at the surfaces more carefully, perhaps as the real sites for the generation of meaning. He goes so far as to connect the experience of ground and air as a crucial way of knowing and ties human culture intrinsically to the materiality surrounding it (Ingold, 2010; 2012). Surfaces become complex, multifarious zones of exchange where materiality becomes entwined with representations, sensations and affects (Forsyth et 
al., 20I3). The way we treat the surfaces - in other words, control the weather - can be also seen as a direct expression of ecological as well as aesthetic and moral values. Both absence and presence of human traces on the surfaces of the earth are devices for taking claims to space (Brown, 20I4).

In order to examine the instrumental use-value of the surfaces especially for wellbeing, I turn towards the concept of affordance. Gibson (1979) proposed that people recognize opportunities for action in the environment by perceiving the affordances of either objects within the environment or the environment itself. For an environment to be preferred over others it must afford the functions that are important and meaningful to individuals and might also afford activities that other environments do not support (Clark \& Uzzell, 2002). The concept of affordance suggests that the affordances persist within the object even when no one is using them, and even if no one designed these particular uses. Even pleasure and beauty can be considered as environmental affordances (Grahn \& Stigsdotter, 20l0) because they reflect an assessment of the environment in terms of its compatibility with human needs and purposes, which consequently affects effective human functioning in the settings. This illustrates well both the complexity and the usability of the concept as affordances aim to overcome the artificial dichotomy between an actor and the environment. In this sense, affordances can be hard to specify, but they rather form a conceptual framework for the relationship between built environments and humans over time, especially with respect to the form, function, and meaning of architectural elements. (Maier et al., 2009).

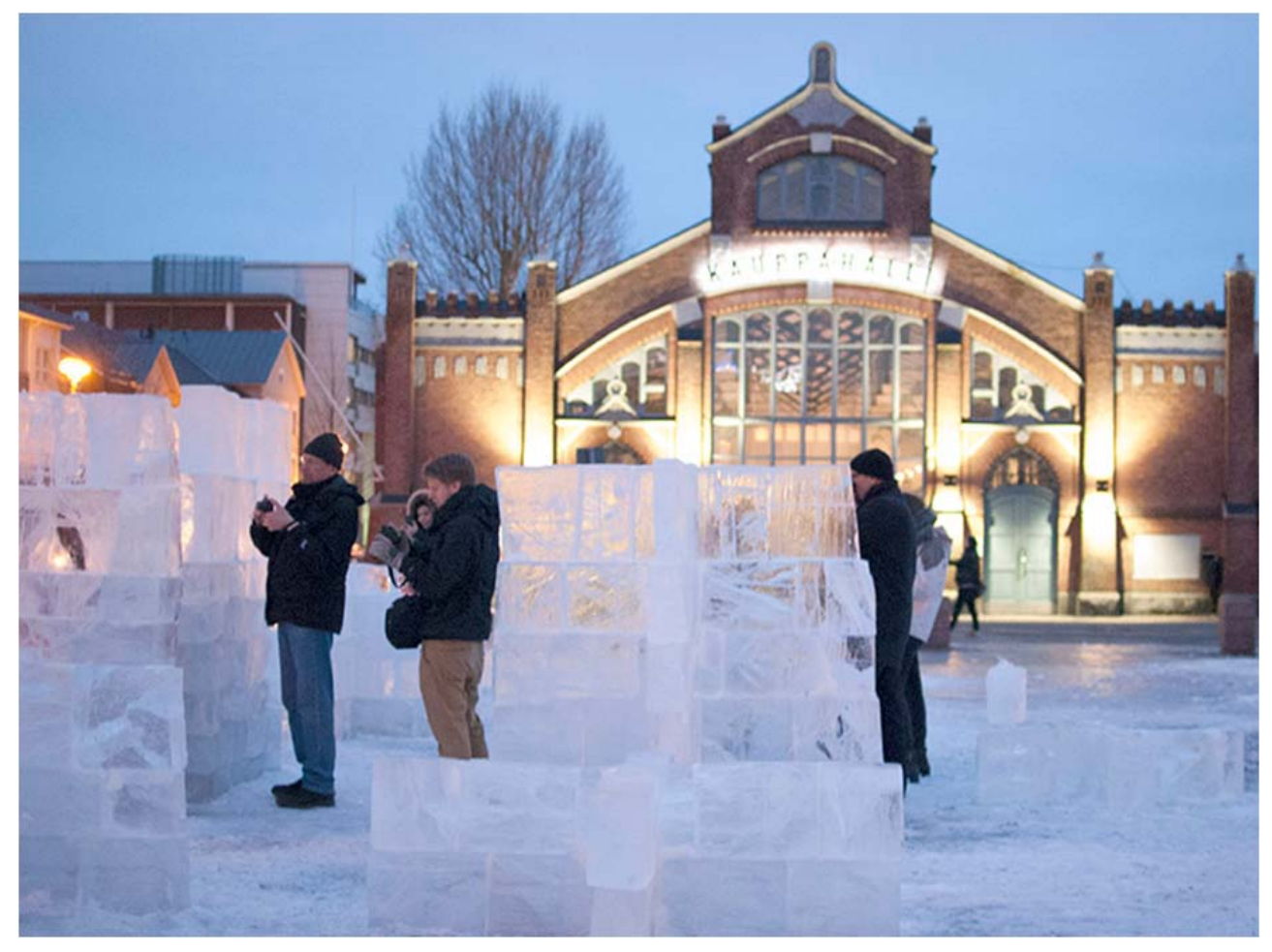

Figure 2. Ice sculpture on the market square highlights the seasonality of the urban space. (Oulu) (Source: Essi Oikarinen) 


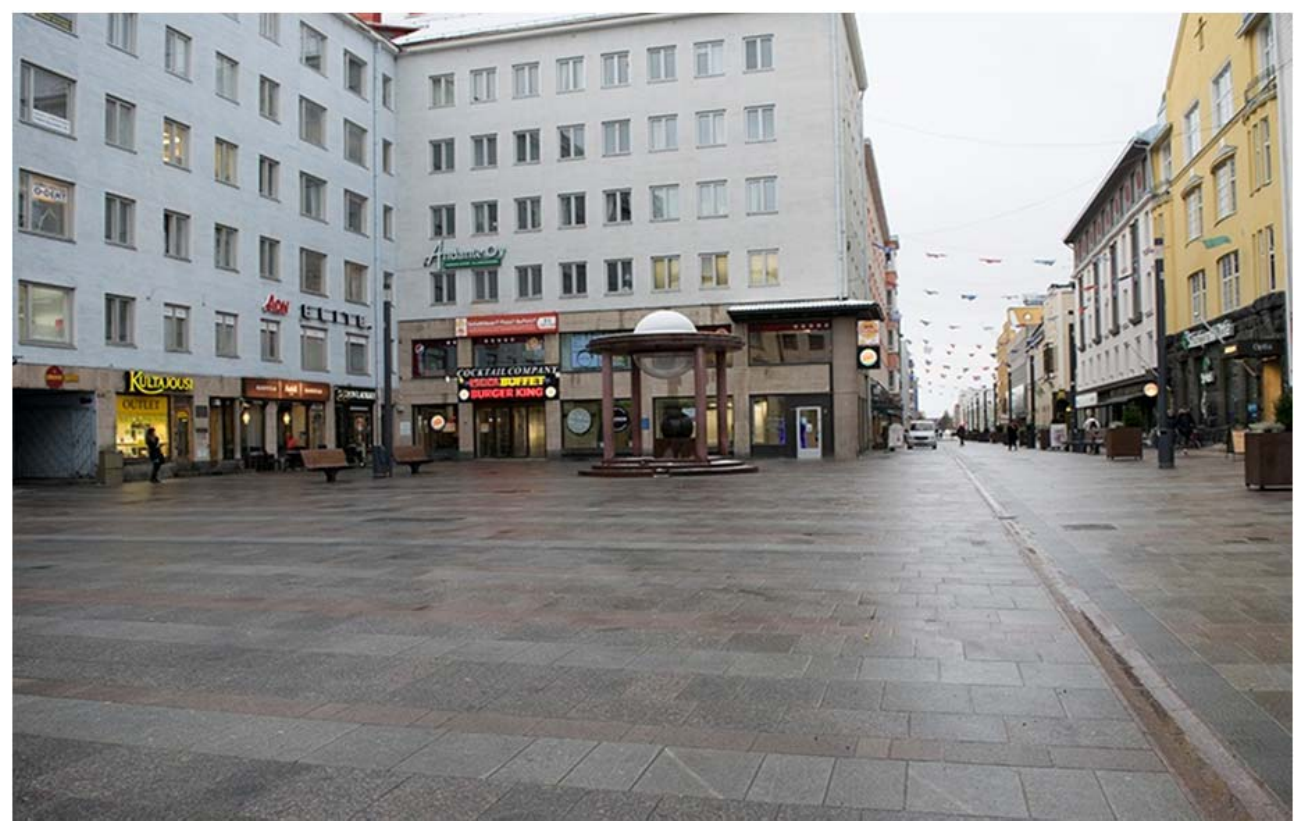

Figure 3. The heated pavement of the pedestrian street keeps the walking conditions similar all year round. The surface eases walkers and strollers to access the street in all weather conditions yet it is aesthetically poor (Oulu). (Source: Essi Oikarinen)

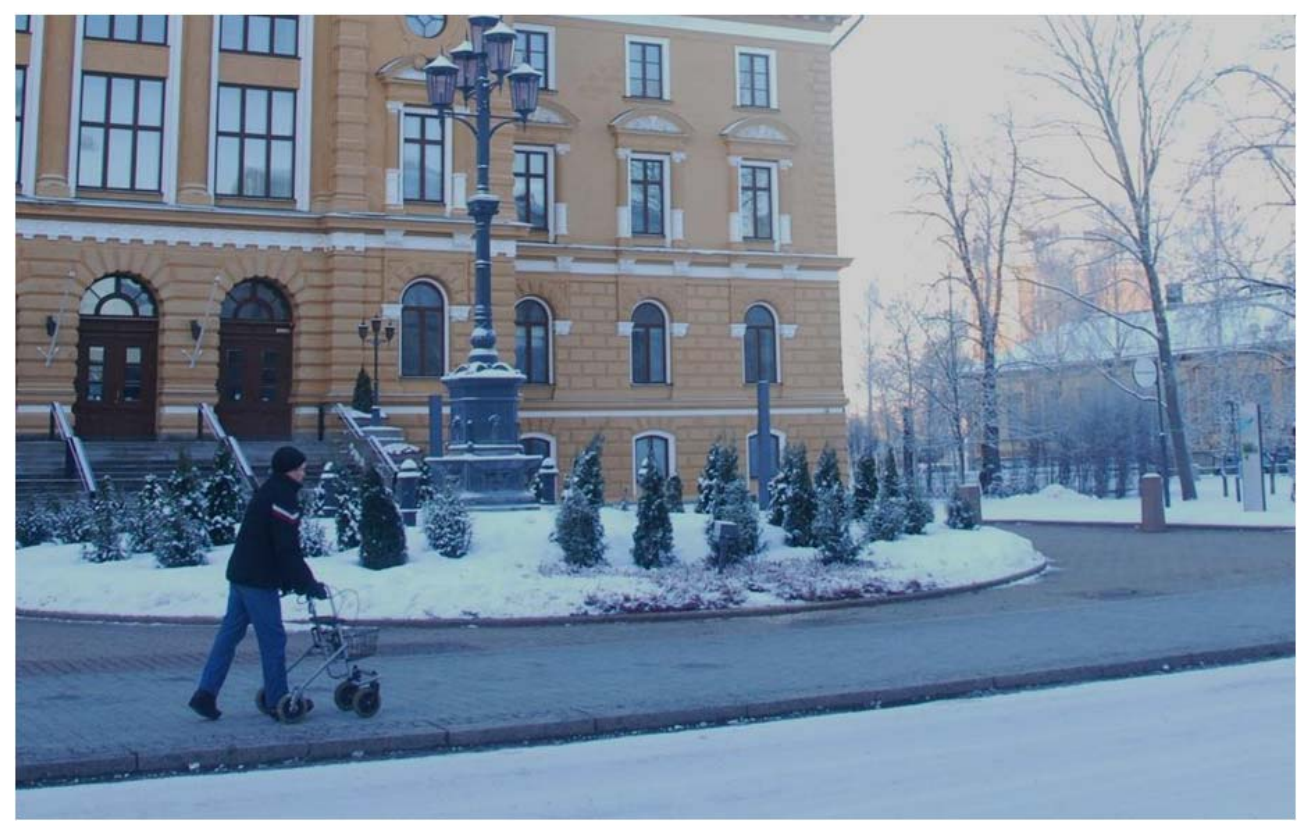

Figure 4. The pavement in front of the City Hall is heated. The limits between heated surface and snow-covered surfaces raise questions about hierarchies: who is the walkability and ease of moving meant for? (Oulu)

(Source: Essi Oikarinen) 


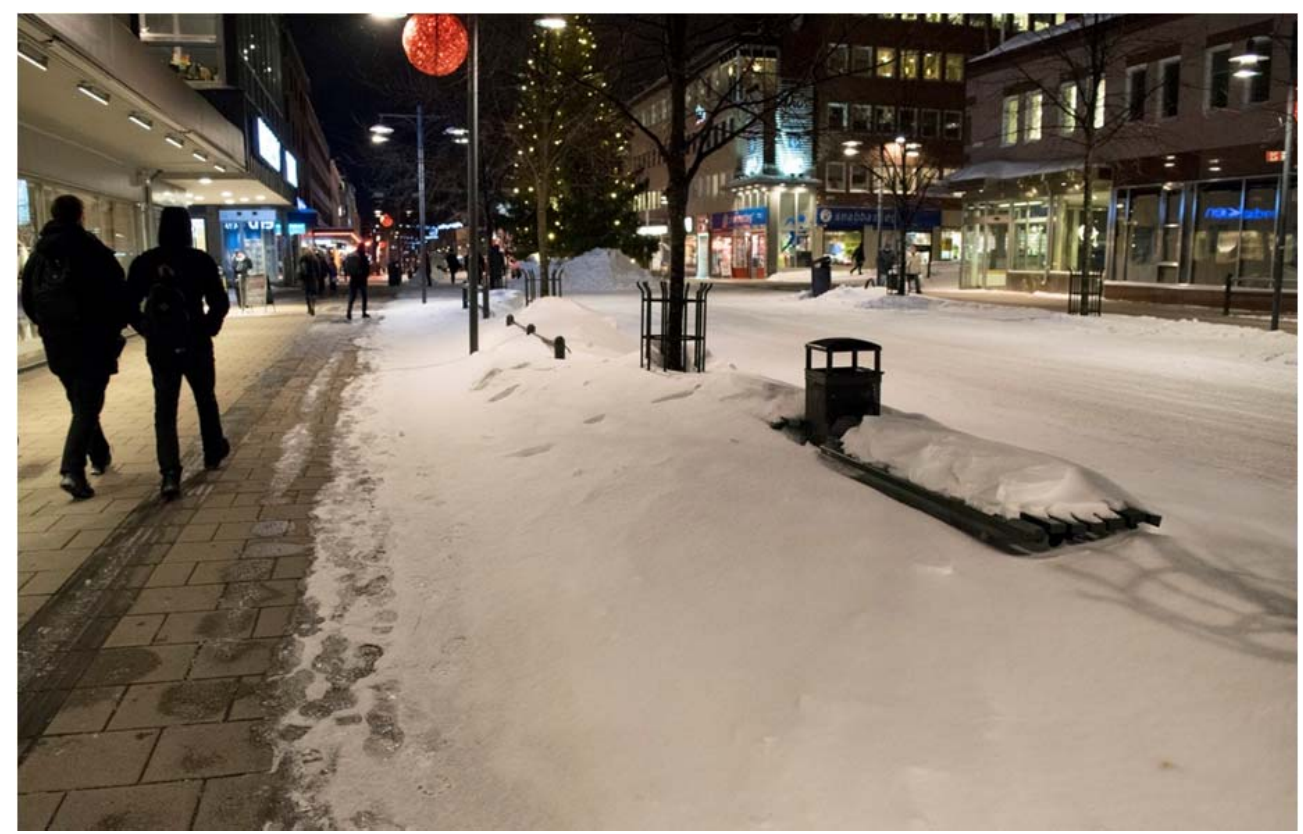

Figure 5. The sidewalk next to the brick and mortar commerce windows is heated to provide easy access to the shops. The snowy section in the middle of the wide pedestrian street enables winter transport (Luleå). (Source: Essi Oikarinen)

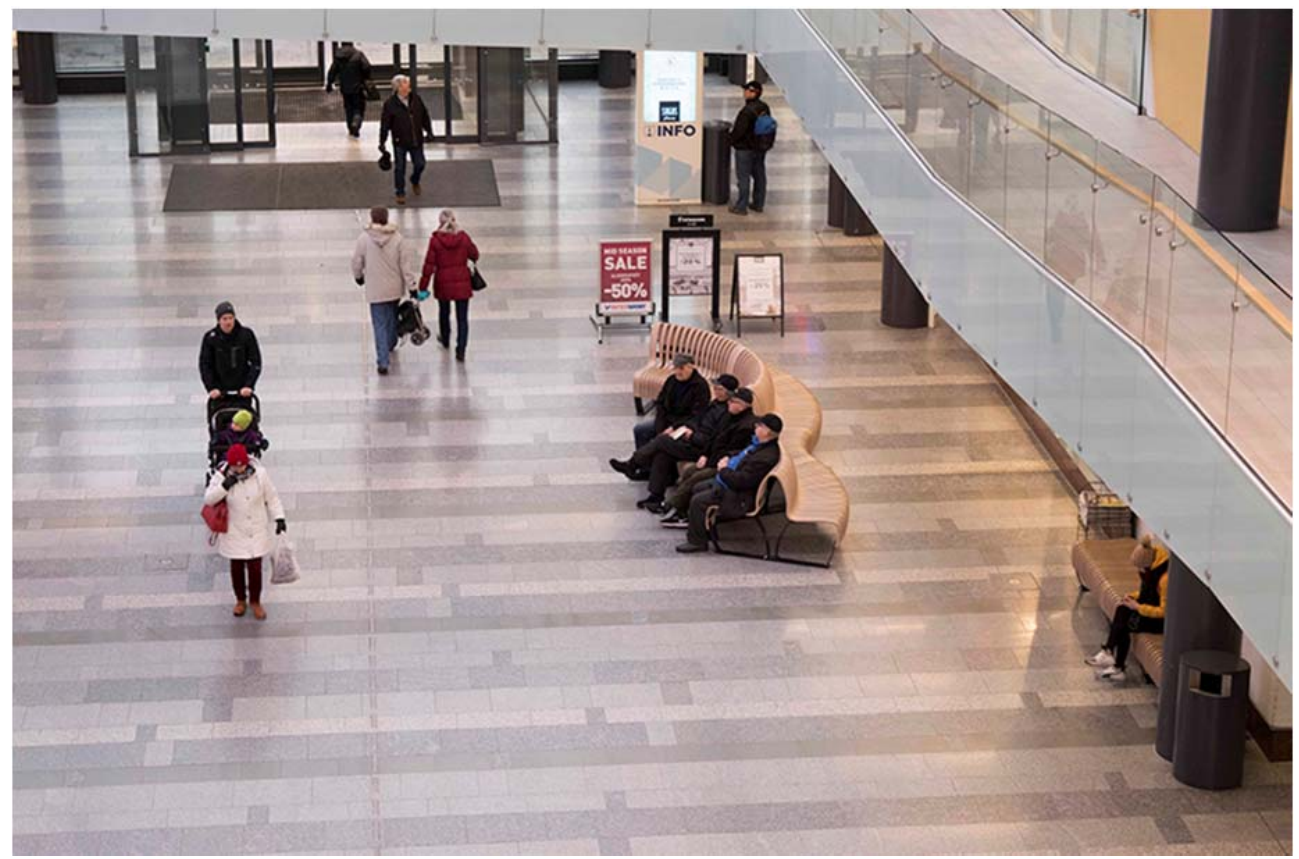

Figure 6. The warm indoor street of a shopping mall affords a warm place to socialize. A street musician and a couple distributing religious leaflets are located just outside the entrance, apparently not feeling welcome by the controlled environment. In addition to sitting, people also use the indoor street created by the shopping centre ground floor as a warm shortcut from one street to another (Oulu). (Source: Essi Oikarinen) 


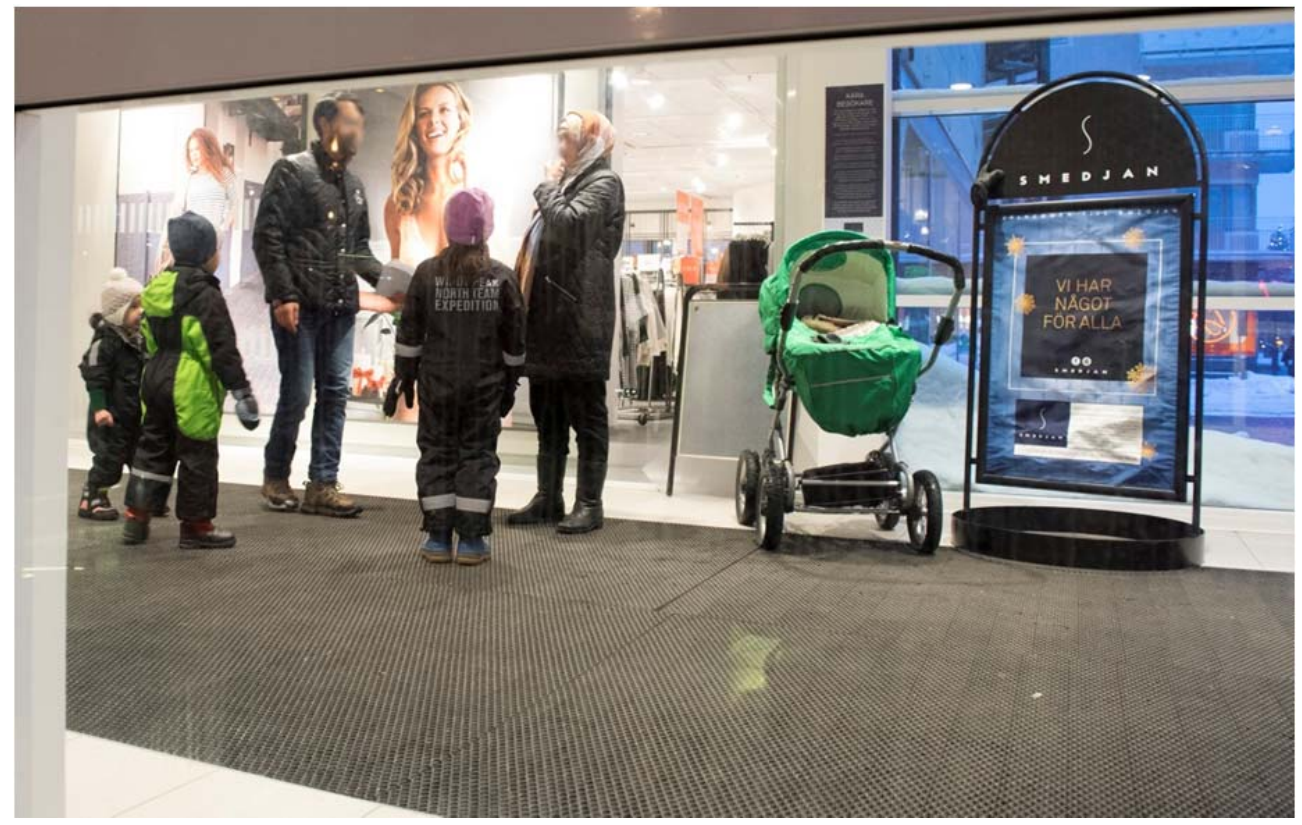

Figure 7. Family is warming up in a vestibule before the shopping centre opens in the morning (Luleå). (Source: Essi Oikarinen)

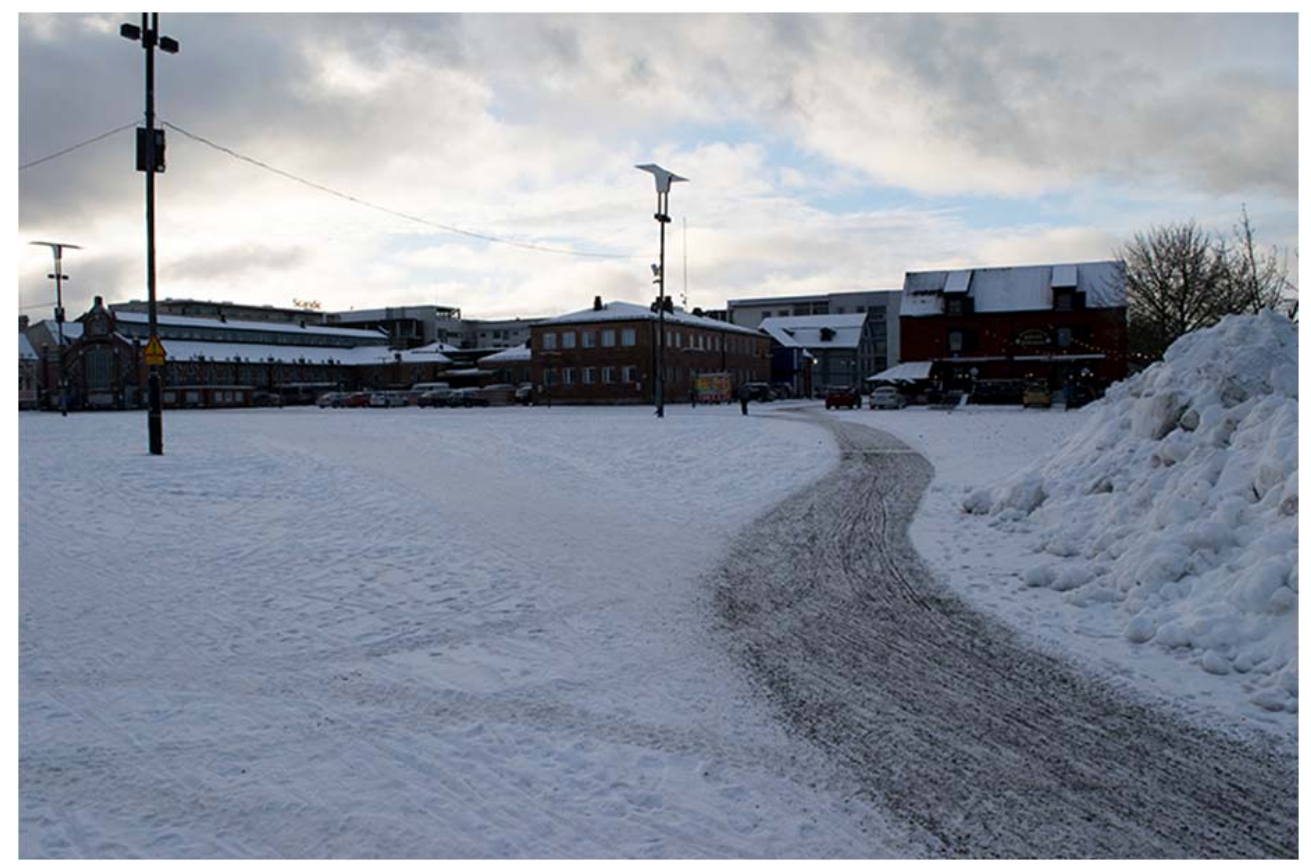

Figure 8. Market square is empty during the winter. The maintained, sanded surface is strictly limited. For the rest of the area, there is no official winter maintenance, which is announced with signs, yet footsteps in the snow show that people have also taken shortcuts instead of using the official route (Oulu). (Source: Essi Oikarinen) 
Roofing and thawing the sub-Arctic city

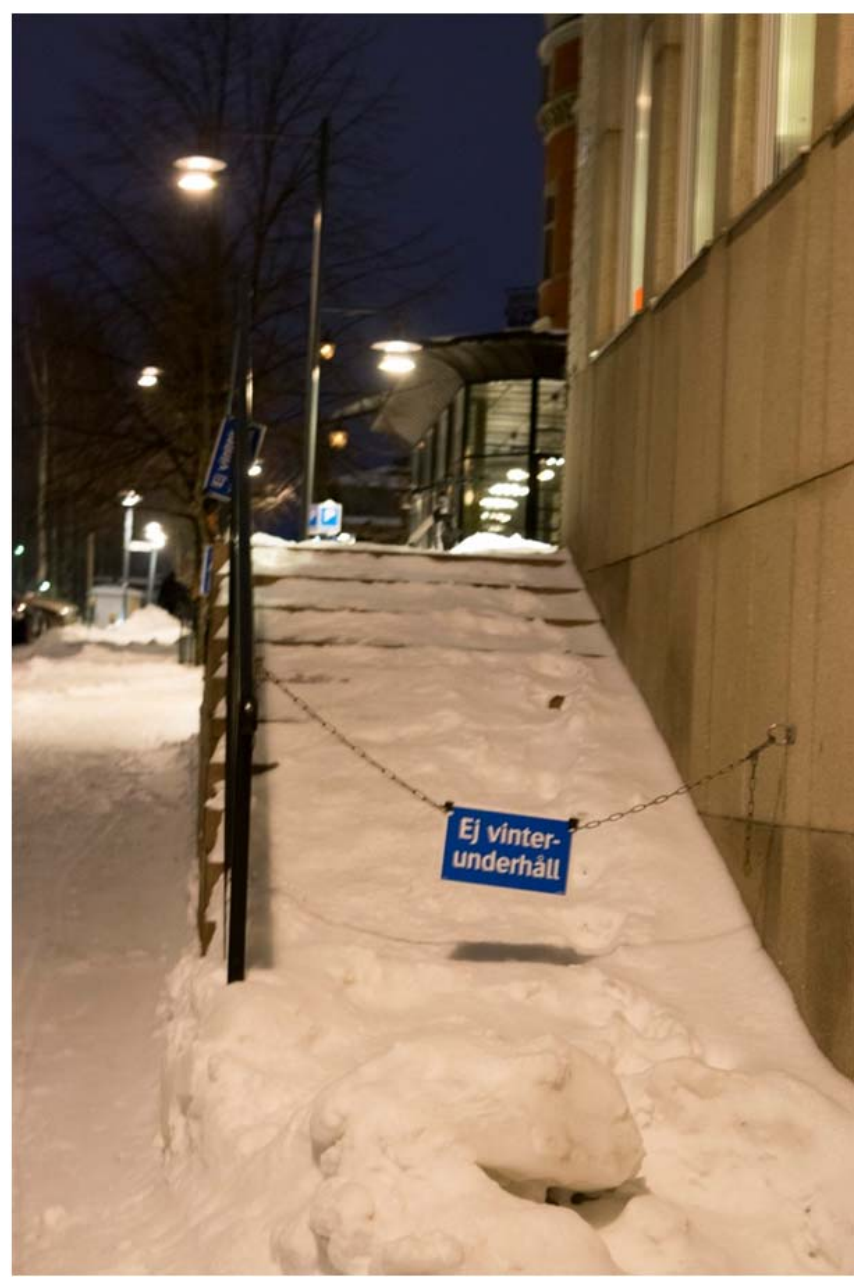

Figure 9. A 'no winter maintenance' sign and fence will not stop using the routes also used during the summer season if they provide a shortcut (Luleå). (Source: Essi Oikarinen)

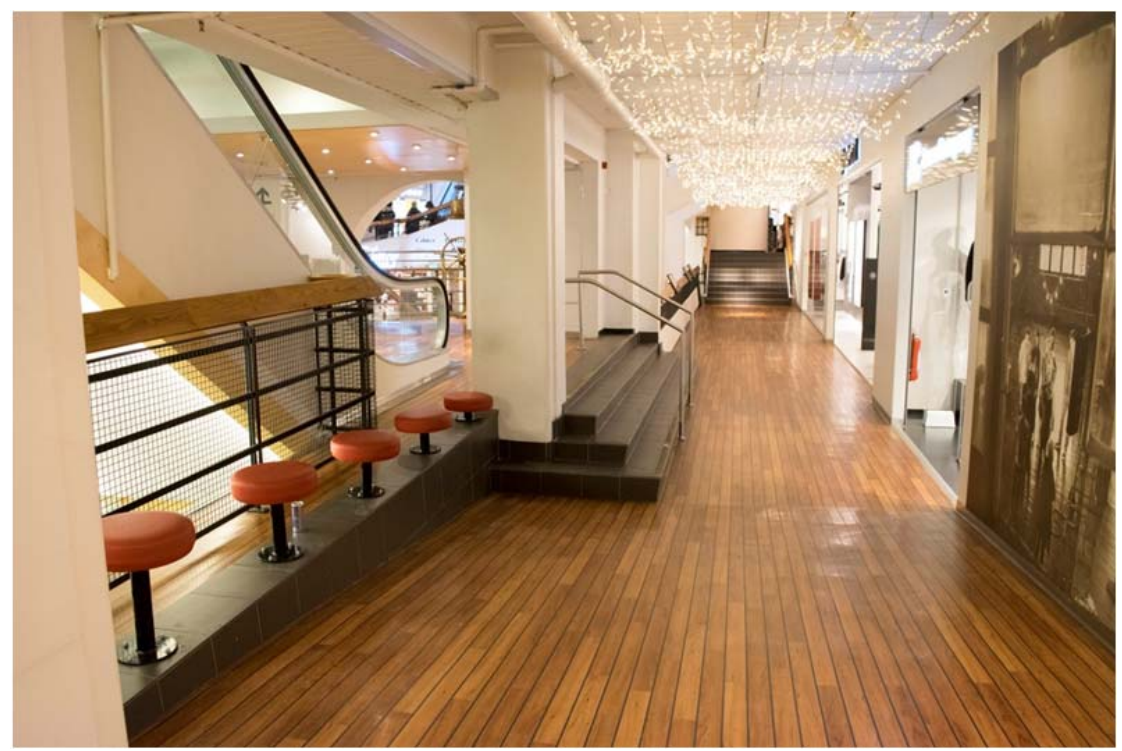

Figure 10. Christmas lights add a hint of seasonality to otherwise static indoor space in a shopping centre (Luleå). (Source: Essi Oikarinen) 
Table I. The table summarises notions on the affordances of different surficial conditions of sub-Arctic urban realm during the winter season. The order is from the most processed to the most 'natural' surface.

\begin{tabular}{|c|c|c|c|c|}
\hline $\begin{array}{l}\text { Surface } \\
\text { type }\end{array}$ & $\begin{array}{l}\text { Spatial } \\
\text { examples }\end{array}$ & $\begin{array}{l}\text { Distinguishing } \\
\text { characteristics }\end{array}$ & $\begin{array}{l}\text { Positive } \\
\text { affordances }\end{array}$ & $\begin{array}{l}\text { Negative } \\
\text { affordances }\end{array}$ \\
\hline $\begin{array}{l}\text { Roofed, } \\
\text { protected }\end{array}$ & $\begin{array}{l}\text { Shopping } \\
\text { mall, arcade } \\
\text { (Figures 6, } \\
7,10)\end{array}$ & $\begin{array}{l}\text { (Often) commercial } \\
\text { space, where free } \\
\text { lingering is controlled. }\end{array}$ & $\begin{array}{l}\text { Warming, using } \\
\text { as a shortcut. }\end{array}$ & $\begin{array}{l}\text { Only well- } \\
\text { mannered } \\
\text { staying is } \\
\text { allowed. }\end{array}$ \\
\hline Defrosted & $\begin{array}{l}\text { Defrosted } \\
\text { pavement, } \\
\text { salted road } \\
\text { (Figures 3, 4, } \\
\text { 5) }\end{array}$ & $\begin{array}{l}\text { Paved or asphalted } \\
\text { surfaces that are kept } \\
\text { permanently in their } \\
\text { 'summer state'. The } \\
\text { user is attracted to } \\
\text { use certain routes. }\end{array}$ & $\begin{array}{l}\text { Easy, equal soft } \\
\text { mobility options } \\
\text { are available } \\
\text { (such as } \\
\text { skateboarding) } \\
\text { during all } \\
\text { seasons. }\end{array}$ & $\begin{array}{l}\text { Aesthetically } \\
\text { detached from } \\
\text { the nature, } \\
\text { aesthetically } \\
\text { poor. }\end{array}$ \\
\hline Sanded & $\begin{array}{l}\text { Paths, } \\
\text { passages for } \\
\text { light traffic } \\
\text { (Figure 8) }\end{array}$ & Sand on snow or ice. & $\begin{array}{l}\text { Easy, equal } \\
\text { walking imitates } \\
\text { the summer } \\
\text { setting in its } \\
\text { functionality. } \\
\text { enables i.e. bike } \\
\text { riding all year } \\
\text { round. }\end{array}$ & $\begin{array}{l}\text { Winter modes } \\
\text { of moving such } \\
\text { as sledding or } \\
\text { skiing are not } \\
\text { supported. } \\
\text { Small stones get } \\
\text { into shoes. }\end{array}$ \\
\hline $\begin{array}{l}\text { Manufactured } \\
\text { snow or ice }\end{array}$ & $\begin{array}{l}\text { Skating rink, } \\
\text { sledding hill, } \\
\text { ice sculpture } \\
\text { (Figure 8) }\end{array}$ & $\begin{array}{l}\text { Formations and } \\
\text { surfaces that enable } \\
\text { wintery ways of } \\
\text { moving or touching. }\end{array}$ & $\begin{array}{l}\text { Play, movement, } \\
\text { faster means of } \\
\text { transport (i.e. } \\
\text { pulling a child in } \\
\text { sled). }\end{array}$ & $\begin{array}{l}\text { Not equally } \\
\text { accessible for } \\
\text { everyone. }\end{array}$ \\
\hline $\begin{array}{l}\text { Non- } \\
\text { maintained } \\
\text { (i.e. snowy or } \\
\text { icy) }\end{array}$ & $\begin{array}{l}\text { Iced water } \\
\text { bodies and } \\
\text { other } \\
\text { deformations } \\
\text { of nature, } \\
\text { forests, non- } \\
\text { winter- } \\
\text { maintained } \\
\text { paths and } \\
\text { routes } \\
\text { (Figure 9) }\end{array}$ & $\begin{array}{l}\text { Surfaces that have no } \\
\text { winter maintenance, } \\
\text { or surfaces that are } \\
\text { completely deformed } \\
\text { by nature, such as iced } \\
\text { lakes. }\end{array}$ & $\begin{array}{l}\text { Places become } \\
\text { more accessible, } \\
\text { possible to use } \\
\text { shortcuts (i.e. } \\
\text { through iced } \\
\text { lakes), enable } \\
\text { new } \\
\text { perspectives to } \\
\text { the city, enable } \\
\text { occupation of } \\
\text { unstamped } \\
\text { terrains. }\end{array}$ & $\begin{array}{l}\text { Not equally } \\
\text { accessible for } \\
\text { everyone. } \\
\text { (Piles) often } \\
\text { reduce the flat } \\
\text { and accessible } \\
\text { surfaces in the } \\
\text { city. }\end{array}$ \\
\hline
\end{tabular}

Current conceptions of health and wellbeing acknowledge the need for control over one's own physical, mental, social and spiritual health, which provides a good starting point for looking at wellbeing through affordances: humans are given an active role in their endeavours towards achieving health and wellbeing. Mundane surfaces of everyday life rarely draw attention to themselves, are often not of "spectacular novelty, technical 
exceptionality, iconic imagery or transgressive audacity" (Ingold 2017, p. 100) yet they form the stage for human life - and are also a stage where to perceive weather events. Table I summarises notions on the affordances of different surficial conditions of subArctic urban realm during the winter season.

\section{Discussion: Wellbeing affordances of sub-Arctic urban surfaces}

Examining the urban surficial situations on a mundane everyday micro level reveals arbitrary situations, which do not follow from any comprehensive plan. The inhabitants of the space have more agency than traditional conceptions of urban space acknowledge. Sub-Arctic city surfaces get re-made all the time because of seasonality and weather changes - and inhabitants have active role in re-making them. Winter urban realm is often maintained with different level categories and increasingly focussed on mobility - but this kind of planning is often slightly larger in scale. The urban grain becomes coarser during winter (Chapman et al., 2019) - but this is seemingly not the case of everyday activity. People stop to warm themselves in vestibules while waiting for something or cross through warmed indoor spaces on their routes. They create paths where there was an access during summer as well or continue using passages and stairs that are not maintained during winter and sometimes closed with fences and signs, even if this means slightly more difficult moving conditions - to mention only some of the non-planned uses. Producing active and inviting environments all year round requires understanding of small scale and in-between situations of the wintry urban realm. Examining urban realm as an entity of surfaces instead of, for example, the dichotomy of protection and exposure, the conception of 'good' environment becomes broader. Artificial environments which are free from the effects of weather, such as shopping centres, have been criticised for the privatisation of public space and the erosion of the public sphere (Chiodelli \& Moroni, 20I5), extending the use of control systems used in private spaces to public spaces (Boddy, 1992) or, specifically in the context of northern cities, resulting in placeless environments not stemming from their cultural context or possessing genuine meaning for inhabitants (Pressmann, 1996). While the critique can be also opposed (i.e. Chiodelli \& Moroni, 20I5), shopping centres are not discussed systematically as contributors of wellbeing, but rather through control. Even though some activities within these semi-public and private indoor spaces are controlled, people still have some control over their own activities, and find affordances that benefit their own wellbeing yet are within the allowed range. This includes, for example, using the routes through shopping malls as warmed shortcuts. These reveal tactics of urban survival and enjoyment. This kind of approach supports including climate as a central part of culturally and socially produced places.

\section{Conclusions}

Through a review of the literature, this paper proposes surfaces as a useful perspective for discussing to sub-Arctic urban realm and its health and wellbeing-enhancing features. The concept of surface also acknowledges the activity happening in the space, connecting urban form, climate and the inhabitants. It provides a perspective on how the initial intentions or objectives of the design relate with how the artefact is actually used - which cannot be approached by looking at the planned environment only, or just 
the spaces themselves as physical entities. In this way, 'thinking through the weather' diverts clearly from the traditional form-based discussions of urban design and architecture. Sub-Arctic urban space cannot be conceived as dichotomies such as indoor vs. outdoor space or even through public vs. private. This also brings up Matthew Carmona's (2010) point on the over and under management of urban realm: the spaces can also have various uses and the limits of public and private, for example, get blurred. This kind of examination could be central, for example, when developing soft mobility plans for northern regions. Could commercial space have some further imposed claims in sub-Arctic climate? Could the private actors be demanded for more? Also, the in-between spaces resulting at the entrances of warm indoor spaces might require a more detailed consideration in design. Private institutions, such as shopping malls, also play part in forming the public sphere (Chiodelli and Moroni, 20I5). In the future, further conceptualisations of the micro-relationships of urban realm might also benefit from testing the concept also at edges of the city. There, environments are even more seasonal, since the nature is often more present.

Sub-Arctic climate is just one among many, and in this sense, the proposed direction of examining the effects of climate on urban life might be applicable elsewhere, as well. On the other hand, sub-Arctic climate is a zone where no particular urban language exists (at least explicitly stated), but the solutions originate from warmer climates. As climate is so strong part of the urban realm, this kind of re-examination of relationships between urban form and climate and users could result in completely new urban aesthetics.

This paper is explorative by nature; therefore, the proposed framework should be tested with further research. While presenting a surface-based approach to urban space, this article also opens up a lot of questions, for example regarding sustainability. What would be the most economical way to organise the urban realm? Are energyintensive, warmed and roofed spaces ecologically viable, if they also encourage people to consume less or use the means of soft mobility? Also, examining different user groups with differing needs would be highly beneficial.

Traditionally, public space is thought to act as communication space. When closed indoors, it does not communicate ecological values and detaches people from their surroundings. The relationship to nature and its processes is central and can also eventually enhance socio-technical performance of a system (Anusas \& Ingold, 20I3). Therefore, this paper also primes viewpoints on experiencing nature. Including climaterevelatory elements in design can communicate the ever-changing patterns of microclimate; make them more 'experience-able' and thus also raise people's awareness of the microclimate patterns themselves (Lenzholzer, 2010). What should the relationship between climate-revelatory elements and environments detached from the effects of climate be in an ideal urban space?

As pointed out in this paper, knowledge on experiences and preferences is often hyper local, and therefore contrasting with the knowledge on environment and climate (Younger et al., 2008), which are often discussed in the context of (global) climate change. By letting the climatic effects show also in the urban realm, contemporary western societies could be more connected to nature. Neither is climate change just about large area adaptation, but as much about practical and aesthetic small life relations - which this paper aims to conceptualise. 


\section{References}

99\% Invisible (2019). Episode 363: Invisible Women. Online article. Accessed 27 Apr 2020, https://99percentinvisible.org/episode/invisible-women/.

Anusas, M and Ingold T. (20I3). Designing Environmental Relations: From Opacity to Textility. Design Issues, 29, 4, pp. 58-69.

Biehler, D D, Simon, G L. (2010). The Great Indoors: Research frontiers on indoor environments as active political-ecological spaces. Progress in Human Geography, 35, 2, pp. 172-192.

Boddy, T. (1992). Underground and Over Head. Building the Analogous City. Variations on a Theme Park (Sorkin, M, ed). 4th edition. New York, Hill \& Wang.

Brown, K M. (20I5). Leave only footprints? How traces of movement shape the appropriation of space. Cultural Geographies, 22, 4.

Carmona, M, Heath, T, Oc, T, \& Tiesdell, S. (2003). Urban Spaces - Public Places: The Dimensions of Urban Design. Oxford, Architectural Press.

Carmona, M. (2010). Contemporary Public Space: Critique and Classification, Part One: Critique, Journal of Urban Design, 15, I, Pp. I23-I48.

de Certeau, M. (1984). The Practice of Everyday Life. Berkeley, University of California Press. (Originally published in French as L'invention du quotidien. Vol. I, Arts de faire, 1980)

Chapman, D. (2018). Urban Design of Winter Cities: Winter Season Connectivity for Soft Mobility. $\mathrm{PhD}$ thesis, Luleå University of Technology.

Chapman, D; Nilsson, K, Larsson, A, \& Rizzo, A. (2017). Climatic barriers to soft-mobility in winter: Luleå, Sweden as case study. Sustainable Cities and Society, 35 (Nov), pp. 574-580.

Chapman, D, Larsson, A. (2019). Toward an Integrated Model for Soft Mobility. International Journal of Environmental Research and Public Health, 16, 10.

Chapman, D, Nilsson, K L, Rizzo, A \& Larsson, A. (2019). Winter City Urbanism: Enabling All Year Connectivity for Soft Mobility. International Journal of Environmental Research and Public Health, 16, 10.

Chiodelli, F \& Moroni, S. (20I5). Do malls contribute to the privatisation of public space and the erosion of the public sphere? Reconsidering the role of shopping centres. City, Culture and Society, 6, pp. 35-42.

City of Edmonton. (2012). Winter Design Guidelines: Transforming Edmonton into a Great Winter City.

City of Oulu. (20I4). Talvikaupunkistrategia. Hiukkavaaran keskus - kestävä pohjoinen talvikaupunki. Oulun kaupunkisuunnittelu, sarja b 46. Accessed 27 Apr 2020, https://www.ouka.fi/c/document library/get_file?uuid=6e723047-0378-450b-ad62$\underline{5 c 4 f d 5 e 32 a e 3 \& g r o u p l d}=139863$

Clark, C \& Uzzell, D. (2002). The affordances of the home, neighborhood, school and town center for adolescents. Journal of Environmental Psychology, 22, Pp. 95-108.

Eliasson, I. (2000). The use of climate knowledge in urban planning. Landscape and Urban Planning, 48, pp. $31-44$. 
Eliasson, I, Knez, I, Westerberg, U, Throsson, S \& Lindberg, F. (2007). Climate and behaviour in a Nordic city. Landscape and Urban Planning, 82, pp. 72-84.

Ebrahimabadi, S. (2015). Outdoor Comfort in Cold Climates. Integrating Microclimate Factors in Urban Design. PhD Thesis. Luleå University of Technology.

Ebrahimabadi, S; Nilsson, K \& Johansson, C. (2015). The Problems of Addressing Microclimate Factors in Urban Planning of the Subarctic Regions. Environment and Planning B: Urban Analytics and City Science, 42, 3.

Evans, G W \& McCoy, J M. (1998). When buildings don't work: the role of architecture in human health. Journal of Environmental Psychology, 18, pp. 85-94.

Eriksson, M \& Lindström, B. (2007). Antonovsky's Sense of Coherence Scale and It's relation with quality of life: A systematic review. Journal of Epidemiology and Community Health, 6I, Pp. 938-944.

Forsyth, I, Lorimer, H, Merriman, P \& Robinson, J. (20I3). What are surfaces? Environment and Planning A, 45, 5, pP. I0I3-I020.

Gehl, J. (I97I). Life between buildings - Using public space. Washington DC, Island Press, 201 I.

Gibson, J J. (1979). The Ecological Approach to Visual Perception. New York, Psychology Press \& Routledge Classic Editions 2015.

Grahn, P \& Stigsdotter, U K. (2010). The relation between perceived sensory dimensions of urban green space and stress restoration. Landscape and Urban Planning, 94, 3-4, pp. 264275.

Ingold, T. (2017). Surface Visions, Theory, Culture \& Society, 34, 7-8, pp. 99-108.

Ingold, T. (2012). Toward an Ecology of Materials. Annual Review of Anthropology, 4I, pp. 427442.

Ingold, T. (2010). Footprints through the weather-world: walking, breathing, knowing, Journal of the Royal Anthropological Institute (N.S.), pp. I2I-139

Jauhiainen, J S \& Mönkkönen, M. (2005). Seasonality: Nature, People's Preferences and Urban Planning in Oulunsalo, Finland, Landscape Research, 30, 2, pp. 273-28I.

Kohl, H W et al. (20I2). Lancet Physical Activity Series Working Group, The pandemic of physical inactivity: Global action for public health, Lancet, 380, pp. 294-305.

Kuismanen, K. (2008). Climate conscious architecture design and wind testing method for changing climates. PhD Thesis, University of Oulu.

Labadini, A. (2017). Immaterial landscapes: Formulating the Intangible in Northern Landscapes. PhD Thesis, The Oslo School of Architecture and Design.

Lefebvre, H. (1992). Rhythmanalysis: Space, Time and Everyday Life. Bloomsbury Academic.

Lefebvre, H., \& Nicholson-Smith, D. (199I). The Production of Space (vol. 142). Oxford, Blackwell. Lenzholzer, S. (2010). Designing Atmospheres. Research and Design for Thermal Comfort in Dutch Urban Squares. PhD Thesis, Netherlands Research School for the Socio-Economic and Natural Sciences of the Environment (SENSE).

Lenzholzer, S. (20I2). A city is not a building - architectural concepts for public square design in Dutch urban climate contexts, Journal of Landscape Architecture, 3, I, pp. 44-55. 
Li, S. (1994). Users' Behaviour of Small Urban Spaces in Winter and Marginal Seasons. Architecture and Behavior, 10, I, PP. 95-109.

Pressman, N. (1996). Sustainable winter cities: Future directions for planning, policy and design, Atmospheric Environment, 30, pp. 521-529.

Loughran, K. (2016). Imbricated Spaces: The High Line, Urban Parks, and the Cultural Meaning of City and Nature, Sociological Theory, 34, 4, pp. 3I I-334.

Maier, J R A, Fadel, G M \& Battisto, D G. (2009), An affordance-based approach to architectural theory, design, and practice. Design Studies, 30, pp. 393-4I4.

Mäkinen, T M. (2007). Human cold exposure, adaptation and performance in high latitude environments, American Journal of Human Biology, 19, pp. I55-164.

Roesler, S. (2016). The Urban Microclimate as Artefact: Reassessing Climate and Culture Studies in Architecture and Anthropology, Architectural Theory Review, 2I, I, pp. 73-88.

Thompson Coon, J, Boddy, K, Stein, K, Whear, R, Barton, J \& Depledge, M H. (20I I). Does Participating in Physical Activity in Outdoor Natural Environments Have a Greater Effect on Physical and Mental Wellbeing than Physical Activity Indoors? A Systematic Review, Environmental Science and Technology, 45, Pp. I76I-I772.

Thorsson, S, Honjo, T, Lindberg, F, Eliasson, I \& Lim, E-M. (2007). Thermal comfort and outdoor activity in Japanese urban public places, Environment and Behavior, 39, 5, pp. 660684.

United Nations (2016). New Urban Agenda. Adopted at the United Nations Conference on Housing and Sustainable Urban Development (Habitat III) in Quito, Ecuador, on 20 October 2016.

Volker, S \& Kistemann, T. (20II). The impact of blue space on human health and well-being Salutogenetic health effects of inland surface waters: A review, International Journal of Hygiene and Environmental Health, 214, pp. 449-460.

Watson, S. (2017). Liquid passions: bodies, publics and city waters, Social \& Cultural Geography, 20, 7, pp. $960-980$.

Westerberg, U. (2009). The significance of climate for the use of urban outdoor spaces: Some results from case studies in two Nordic cities, International Journal of Architectural Research (IJAR), 3, I, Pp. I3I-I44.

Younger, M, Morrow-Almeida, H R, Vindigni, S M \& Dannenberg, A L. (2008). The Built Environment, Climate Change, and Health. Opportunities for Co-Benefit, American Journal of Preventive Medicine, 35, 5, pp. 5I7-526. 